\title{
As tecnologias leves como geradoras de satisfação em usuários de uma unidade de saúde da família*
}

\author{
Sonia Mara Neves Ferri ${ }^{1}$ \\ Maria José Bistafa Pereira ${ }^{2}$ \\ Silvana Martins Mishima ${ }^{3}$ \\ Maria do Carmo Guimarães Caccia-Bava ${ }^{4}$ \\ Maria Cecília Puntel de Almeida ${ }^{5}$
}

FERRI, S.M.N. ET AL. Soft technologies as generating satisfaction in users of a family health unit. Interface Comunic., Saúde, Educ., v.11, n.23, p.515-29, set/dez 2007.

The purpose of this inquiry was to evaluate the quality of the assistance provided in a family health nucleus focusing on user satisfaction with soft technologies. It also aimed at analyzing those aspects of this assistance producing satisfaction and dissatisfaction in relation to bond, accountability, resolution, expectations, relationships, comfort and access, as well as eliciting recommendations for local interventions. Following an overall characterization of the target population, research subjects were selected. Data were collected in semistructured interviews. The approach was qualitative, and the data were organized through the Collective Subject Discourse method. The analysis revealed the importance attributed by service users to soft technologies, but also the need to reduce the waiting time for visits and referrals, as well as to secure access to drugs and to dental care in the service itself. These factors generated great dissatisfaction among users.

KEY WORDS: Consumer evaluation. Consumer satisfaction. Family health.

O objetivo desta investigação foi avaliar a qualidade da assistência prestada em um núcleo de saúde da família (NSF), enfocando a satisfação dos usuários, com base nas tecnologias leves, bem como analisar aspectos dessa assistência, produtores de satisfação e de insatisfação, no que diz respeito ao vínculo, à responsabilização, à resolubilidade, às expectativas, aos relacionamentos, ao conforto e acesso, e identificar recomendações para intervenções locais. Após realizarmos uma caracterização geral da população atendida no serviço em estudo, selecionamos os sujeitos participantes da pesquisa. A coleta de dados deu-se por meio da entrevista semiestruturada. A abordagem foi de natureza qualitativa, e os dados foram ordenados pelo método do Discurso do Sujeito Coletivo (DSC). A análise revela a importância atribuída, pelos usuários do serviço, às tecnologias leves, mas também a necessidade de diminuir o tempo de espera para as consultas e os encaminhamentos e obter o acesso a medicamentos $e$ à atenção odontológica no próprio serviço, fatores que levam à grande insatisfação por parte dos usuários.

PALAVRAS-CHAVE: Avaliação dos usuários. Satisfação do usuário. Saúde da família.

\footnotetext{
${ }^{*}$ Elaborado a partir de Ferri, 2006.

${ }^{1}$ Médica; mestre em Enfermagem em Saúde Pública; médica generalista, preceptora da residência médica em Medicina de Família e Comunidade, Fundação de Apoio ao Ensino, Pesquisa e Assistência, Hospital das Clínicas, Faculdade de Medicina de Ribeirão Preto. Ribeirão Preto, SP. <sn.ferri@gmail.com>

${ }^{2}$ Enfermeira; doutora em Enfermagem em Saúde Pública; professora, departamento de Enfermagem Materno-Infantil e Saúde Pública, Escola de Enfermagem de Ribeirão Preto, Universidade de São Paulo. Ribeirão Preto, SP. <zezebis@eerp.usp.br>

${ }^{3}$ Enfermeira; livre-docente em Enfermagem em Saúde Pública - Gestão e Organização de Serviços de Saúde; professora, departamento de Enfermagem Materno-Infantil e Saúde Pública, Escola de Enfermagem de Ribeirão Preto, Universidade de São Paulo. Ribeirão Preto, SP. <smishima@eerp.usp.br>

${ }^{4}$ Assistente social; doutora em Enfermagem em Saúde Pública; professora, departamento de Medicina Social, Faculdade de Medicina de Ribeirão Preto, Universidade de São Paulo. Ribeirão Preto, SP. <mcbava@fmrp.usp.br>

${ }^{5}$ Enfermeira; livre docente em Enfermagem em Saúde Pública; professora, departamento de Enfermagem Materno-Infantil e Saúde Pública, Escola de Enfermagem de Ribeirão Preto, Universidade de São Paulo. Ribeirão Preto, SP. <cecília@eerp.usp.br>
}

${ }^{1}$ Av. Bandeirantes, 3900

Bairro Monte Alegre - Cidade Universitária

Ribeirão Preto, SP

14.040-902 


\section{Introdução}

No ano de 1978, na Conferência em Alma Ata, emergiu uma proposta internacional como sendo a chave para se atingir a meta dos governos/ organizações internacionais/comunidade mundial, no tocante à saúde do mundo, para se obter melhor qualidade de vida e contribuir para a paz mundial: a Atenção Primária à Saúde (APS), ou melhor, "cuidados primários de saúde" (Starfield, 2004). A APS, então, passa a ser conceituada como a atenção essencial à saúde, baseada em métodos práticos, cientificamente evidentes $e$ socialmente aceitos, e em tecnologias tornadas acessíveis a indivíduos e famílias, na comunidade, por meios aceitáveis $e$ a um custo que as comunidades $e$ os países possam suportar (grifo nosso), independentemente de seu estágio de desenvolvimento (...). Constitui o primeiro contato de indivíduos, famílias $e$ comunidades com o sistema nacional de saúde, trazendo os serviços de saúde o mais próximo possível aos lugares de vida e trabalho das pessoas e constitui o primeiro elemento de um processo contínuo de atenção (OMS, 1979).

Ainda nesse processo de repensar as complexas questões pertinentes ao setor saúde, outros encontros internacionais marcaram o fim do século $\mathrm{XX}$, tais como as conferências de Ottawa, em 1986, e de Bogotá, em 1992, ambas trazendo, como marco principal, "saúde para todos" como direito fundamental do ser humano (Brasil, 1996).

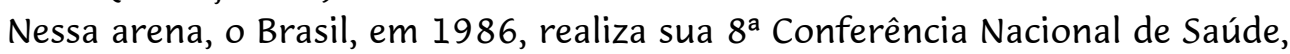
coroando o movimento da Reforma Sanitária, que se iniciou na década anterior, reconhecendo a saúde como um direito de todos e dever do Estado, conceituando a saúde de forma ampliada e demarcando o início da construção do Sistema único de Saúde (SUS), com a legitimação da participação popular. No Brasil, ocorreu um conjunto de reformas administrativas, políticas $e$ organizativas, dentro do campo das políticas públicas da saúde no país, e avançamos muito nos aspectos relativos à legislação (Raggio et al., 1996). Porém, acreditamos que temos um grande desafio a enfrentar para "... mudar o modo como são produzidas as ações de saúde e a maneira como os serviços de saúde e o Estado se organizam para produzi-las e distribuí-las" (Pereira, 2001, p.15).

Nesta perspectiva, o Programa de Saúde da Família, implantado no país desde 1994, constitui-se em mais uma estratégia que se propõe a

$$
\begin{aligned}
& \text {... contribuir para a reorientação do modelo assistencial a partir da atenção } \\
& \text { básica, em conformidade com os princípios do Sus, imprimindo uma nova } \\
& \text { dinâmica de atuação nas Unidades Básicas de Saúde, com a definição de } \\
& \text { responsabilidades entre os serviços de saúde e a população. (Brasil, 1998, p.10) }
\end{aligned}
$$

Na verdade, uma estratégia de política pública de saúde, para viabilizar o que foi preconizado em 1978, em Alma Ata, "saúde para todos no ano 2000", e para reorganizar o modelo de assistência por meio do enfoque na Atenção Primária. Consideramos desafiador enfrentar esta batalha na transformação no modo de se 'fazer saúde' no Brasil, no qual o processo saúde/doença é tido unicamente como um fenômeno individual, centrado no corpo do cliente e fundamentado na visão biomédica; a doença, objeto do processo de trabalho em saúde, e o lucro decorrente dela, a finalidade desse processo (Pereira, 2001). 


\section{Transformação do Modelo Assistencial implica (re)visão do processo de trabalho em saúde}

Apoiando-nos em Merhy et al. (1997), tomamos sua definição de Modelo Assistencial considerando este como a organização dos serviços de saúde com base em um determinado arranjo dos saberes da área, bem como dos projetos de construções de ações sociais específicas e, ainda, como estratégia política de determinados agrupamentos sociais. Portanto, temos claro que, para

(re)construir mudanças, muitas frentes de trabalho são necessárias.

A cultura institucional do modelo tradicional e ainda hegemônico pauta-se por um processo de trabalho em que a prática de atenção está voltada para atender doenças e centrada na queixa-conduta (Almeida, 1991), caracterizada por uma racionalidade linear e mecanicista, recorrendo exclusivamente ao saber biológico e a intervenções técnicas e medicalizantes. Destacamos que essa forma de atendimento é fruto de um longo período histórico, que tem suas raízes no conjunto de dicotomias que atravessa a organização dos serviços de saúde e que vem sendo sustentada pela lógica de mercado, com a finalidade de obtenção de lucro, ficando as necessidades de saúde da população num plano secundário.

Com essas observações, não estamos negando a importância do saber biológico, de intervenções técnicas e medicalizantes. As nossas preocupações são no sentido de não tomar esta questão como única e unilateral, e sim, a partir de um problema, como desencadear um fazer que possa satisfazer às necessidades do usuário na sua singularidade, estabelecendo relações com o emocional, o cultural e o social e canalizando para uma perspectiva coletiva, em busca de uma demanda organizada.

Concordamos com vários autores (Nascimento, 2004; Mehry, 2002; Pessini, 2000), na temática relacionada com o modo de produção dos serviços de saúde, no sentido de que, para (re)construir a prática predominante, é necessário ter a produção de cuidado como a finalidade do processo de trabalho em saúde.

“O que se opõe ao descuido e ao descaso, é o cuidado”,... Boff (1999, p.33)

define o cuidar como uma "atitude de ocupação, preocupação, de responsabilização e de envolvimento afetivo com o outro".

O termo cuidado abrange práticas de saúde que envolvem muitas considerações, isto é, para que as práticas de saúde tenham, como produto final, o cuidado, está implícito que, nos serviços, estejam ocorrendo: o acolhimento, as relações de responsabilidade, a autonomia dos sujeitos envolvidos, as necessidades de saúde, a resolubilidade, o compromisso, o social, o econômico, as políticas públicas, enfim, a integralidade.

Conforme nos traz Pessini (2000, p.236), "cuidar, mais do que um ato isolado, é uma atitude constante de ocupação, preocupação, responsabilização e de envolvimento de ternura com o semelhante". Cabe aqui lembrar que, no ato de cuidar, também existe o ato de curar, porque o biológico não deixou de existir, mas na realidade, como afirmam Silva júnior et al. (2003, p.123): "há uma dificuldade dos profissionais de saúde em lidar com sofrimentos; preferem lidar com doença, na qual a racionalidade da biomedicina estabelece referência e pontos de intervenção sobre as "lesões"e "disfunções" detectadas". Nessa busca de (re)construção da prática de saúde, tendo a produção de cuidado como a finalidade do processo de trabalho em 
saúde, já está implícita a necessidade de incorporar outros instrumentos na produção dos serviços de saúde e, nesse sentido, as tecnologias leves também precisam se constituir em instrumentos do cotidiano da produção dos serviços de saúde.

\section{Tecnologias leves em Saúde}

Mendes-Gonçalves (1994) não restringe o significado de tecnologia ao conjunto de instrumentos materiais do trabalho, e sim o amplia para os saberes e seus desdobramentos materiais e não materiais na produção de serviços de saúde, afirmando que as tecnologias carregam a expressão das relações entre os homens e entre os objetos sob os quais trabalham.

Mehry (2002) toma a definição de tecnologia incluindo, também, os saberes utilizados na produção dos produtos singulares nos serviços de saúde, bem como os saberes que operam para organizar as ações humanas $e$ inter-humanas nos processos produtivos. Este autor a classifica em três tipos: tecnologias duras, leve-duras e leves. Esta forma de referência às tecnologias presentes no trabalho em saúde é apresentada por Mehry, destacando que as tecnologias duras seriam os equipamentos, as máquinas, $e$ que encerram trabalho morto, fruto de outros momentos de produção; dessa forma, conformam em si saberes e fazeres bem estruturados $e$ materializados, já acabados e prontos. As tecnologias leve-duras seriam aquelas referentes aos saberes agrupados que direcionam o trabalho, são as normas, os protocolos, o conhecimento produzido em áreas específicas do saber, como a clínica, a epidemiologia, o saber administrativo e outros; caracterizam-se por conterem trabalho capturado, porém com possibilidade de expressarem trabalho vivo. As tecnologias leves são as produzidas no trabalho vivo em ato, condensam em si as relações de interação $e$ subjetividade, possibilitando produzir acolhimento, vínculo, responsabilização e autonomização. Merhy et al. (1997) afirmam que é necessário imprimir mudanças no processo de trabalho tomando, como eixo analítico vital, o processo de efetivação da tecnologia leve e os seus modos de articulação com as outras tecnologias. Nesse sentido, defendemos que as mudanças serão potencializadas se incorporarmos, no processo de trabalho, as tecnologias leves, no encontro entre trabalhadores e entre estes e os usuários.

Todas essas tecnologias se fazem necessárias nos processos de produção em saúde e, nessa perspectiva, concordamos com Pereira (2001), ao afirmar que não cabe haver hierarquização de valor das tecnologias; a depender da situação, todas são importantes, porém não se deve esquecer de que, em todas as situações, as tecnologias leves precisam estar sendo operadas.

O presente estudo teve como objetivo avaliar a qualidade da assistência prestada no serviço selecionado, enfocando a satisfação da população cadastrada, usuária do serviço avaliado, com base nas tecnologias leves.

\section{A avaliação na perspectiva da satisfação}

Segundo Contandriopoulos et al. (1997), a avaliação é uma atividade tão 
velha quanto o mundo. Ao se revisitar a literatura, nota-se que existem vários conceitos do que seria avaliação. Esses mesmos autores ainda vão além ao dizer que: "Esta breve revisão do estado dos conhecimentos mostra a vaidade que seria propor uma definição universal e absoluta da avaliação (p.31, grifo nosso)"; e ainda afirmam que podemos adotar uma definição que hoje é objeto de amplo consenso, que seria dizer que avaliar consiste em fazer um juízo de valor a respeito de uma intervenção ou sobre qualquer um de seus componentes, com o objetivo de auxiliar na tomada de decisão.

Portanto, a melhoria do atendimento a usuários do sistema de saúde deve ser a motivação principal para se realizar uma avaliação (Hartz, 1997). Neste sentido, vamos ouvir, então, o que os usuários têm a nos dizer, porque suas manifestações certamente não serão uniformes nem constantes, porém trarão consigo fenômenos sociais, expectativas individuais e coletivas, fatores econômicos, políticos e culturais, que certamente influenciarão o resultado a ser alcançado (Oliveira, 1998).

Ao nos posicionarmos afirmando que a qualidade da atenção em saúde se constitui nas dimensões objetiva (representada pelo saber/fazer técnico) $e$ subjetiva (representada pelos aspectos relacionais), estamos defendendo que a produção dos serviços se paute no cuidado, e não em procedimentos. Malik $e$ Schiesari (1998) afirmam que qualquer discussão a respeito de qualidade traz implícita ou explícita a noção de avaliação. Citam, ainda, Donabedian (1990), quando referem três dimensões para a qualidade dos serviços de saúde: $o$ desempenho técnico, ou seja, aplicação do conhecimento e da tecnologia médica, de modo a maximizar os benefícios e reduzir os riscos; as relações interpessoais: o relacionamento com o paciente; $e$ as amenidades: conforto $e$ estética das instalações e equipamentos no local onde a prestação ocorre. A satisfação poderá estar presente ou não, em qualquer uma dessas dimensões, bastando que as expectativas dos usuários em questão tenham sido percebidas e posteriormente resolvidas.

Em 1990, Donabedian define o conceito de qualidade e cita os sete atributos, ou pilares, nos quais esta qualidade repousa: eficácia (o melhor que podemos fazer, em condições mais favoráveis possíveis); efetividade (alcançamos o melhor, porém as condições não foram ideais); eficiência (efeito máximo, no menor custo); aceitabilidade (relaciona-se com a expectativa do usuário: conformidade dos serviços com as aspirações e expectativas dos pacientes $e$ familiares); otimização (criação de condições mais favoráveis para a solução de algum problema); legitimidade (aceitação e aprovação dos serviços de saúde pelos usuários); eqüidade (esforço para diminuir desigualdades).

Segundo Uchimura e Bosi (2002), a dimensão subjetiva da qualidade de programas e serviços - e aqui estaria incluída a avaliação da satisfação dos usuários - ainda é um terreno pouco explorado. Guarda, certamente, "em seus meandros, muitos aspectos a serem desvelados, já que pertence ao mundo das nuanças, do profundo, do particular" (Uchimura \& Bosi, 2002, p.7).

Neste estudo, concordamos, então, com os autores que relacionam a satisfação com fatores psicoculturais, pois acreditamos que poderão, sim, influenciar na percepção dos usuários quanto ao serviço utilizado $e$ influenciarão no julgamento da qualidade do cuidado prestado. Mas também acreditamos que, mudando a forma de produzir esse cuidado, usando a 
qualidade, $e$ não só a quantidade, usando a responsabilidade, $e$ não a dependência, usando o carinho, e não a técnica reservada, a satisfação será o resultado final do processo de trabalho em saúde.

\section{Metodologia}

Trata-se de um estudo descritivo, tipo estudo de caso, com abordagem qualitativa, utilizando a técnica da entrevista semi-estruturada para a coleta de dados.

O estudo foi realizado em uma cidade situada no noroeste do Estado de São Paulo, a $313 \mathrm{~km}$ da capital. A população é de 543.885 habitantes (SEADE: 2005), com 99,47\% vivendo na zona urbana. O município está dividido em distritos de saúde e habilitado para a Gestão Plena do Sistema Municipal, segundo a Norma Operacional de Assistência à Saúde (NOAS/ 2002), última normativa editada pelo Ministério da Saúde.

A Unidade de Saúde estudada está sob responsabilidade técnica $e$ administrativa do Centro de Saúde Escola da Faculdade de Medicina de Ribeirão Preto da Universidade de São Paulo - CSE-FMRP-USP - Unidade Básica e Distrital do Sumarezinho, pertencente à área de abrangência do Distrito Oeste. O Núcleo de Saúde da Família (NSF), em estudo, é um dos cinco núcleos da área básica de abrangência do CSE. Sua equipe conta com um médico, uma enfermeira, dois auxiliares de enfermagem e cinco agentes comunitários de saúde. Como é uma unidade de Saúde que está vinculada à instituição de ensino, pesquisa $e$ assistência, conta com o trabalho de cinco residentes de Medicina de Família e Comunidade, grupos de graduandos de medicina, odontologia, enfermagem $e$ outras instituições que passam em estágios; ainda com pós-graduandos das diversas Unidades do Campus de Ribeirão Preto que estão em trabalho de campo. Isto faz com que a assistência à saúde prestada nessa unidade seja desenvolvida por outros sujeitos que não só os trabalhadores da equipe mínima.

A área de atuação do NSF em estudo é bem diversa, pois abrange três favelas da zona oeste da cidade; ao mesmo tempo abrange uma área mais "nobre", de casas diferenciadas que estão presentes em um dos bairros do território de abrangência. Das cinco microáreas do Núcleo, somente a microárea 2 apresenta todas as famílias em condições de risco, pois estão todas dentro de uma área de favela; as outras microáreas têm uma grande diversidade de classes sociais em sua área de trabalho, fazendo com que as condições de saúde sejam também bem diversas.

A equipe tem 836 famílias informadas no Sistema de Informação da Atenção Básica (SIAB) (Fevereiro - 2004), com um total de, aproximadamente, três mil pessoas cadastradas. Os sujeitos da pesquisa são 18 usuários que utilizaram o serviço pelo menos uma vez, com idade igual ou superior a 18 anos, pertencentes a famílias sorteadas, dentro de uma proporção em cada respectiva microárea, em relação ao total de famílias cadastradas. Foi considerado somente um respondente por domicílio, aquele que primeiramente atendeu ao entrevistador ou, então, a pessoa responsável por quem usa o serviço e que aceitou participar do estudo. Quando houve mais do que um nessas condições, eles mesmos indicaram aquele que participaria da pesquisa, uma vez que seria entrevistada apenas uma pessoa por família usuária do serviço deste estudo. 
Para a ordenação dos dados, utilizamos a orientação metodológica do Discurso do Sujeito Coletivo (DSC), uma proposta de abordagem qualitativa elaborada por Lefèvre et al. (2000). O DSC é um modo legítimo, mas não único, de compreender as representações sociais, e se revela por meio do conjunto de discursos verbais emitidos por pessoas dessa população. Para organizar e tabular os discursos, são utilizadas quatro "figuras metodológicas”, que seriam imprescindíveis para ocorrer uma análise e interpretação desses pensamentos ou depoimentos; são elas: expressõeschave, idéia central, ancoragem e o discurso do sujeito coletivo.

Ao final da ordenação dos dados, obtivemos um total de 61 discursos do sujeito coletivo. Para análise, agrupamos esses discursos por semelhança de idéias, compondo, assim, quatro grandes temas: "As expectativas", "A realidade que temos", "Produção de tecnologias leves", "As sugestões". Nestes grandes temas, ordenamos os DSCs para o cumprimento dos objetivos do estudo.

\section{Resultados e discussão}

No primeiro tema, das expectativas, buscamos significar o que é saúde na visão dos usuários do serviço analisado, pois entendemos que, assim, conseguiríamos coletar a percepção subjetiva que essas pessoas tinham na obtenção de suas expectativas. É importante lembrar aqui que, conforme explicam Souza e Pereira (1999), a idéia que o paciente tem de saúde irá influenciar no julgamento da qualidade. Tanaka (2005) e Santos \& Lacerda

${ }^{6}$ Explicação em sala de aula, durante o curso de Avaliação de Serviços de Saúde, promovido pela Faculdade de Saúde Pública da USP, Curso de Verão, fevereiro de 2005. (1999) citam que, na avaliação da qualidade dos serviços de saúde, sobretudo no que diz respeito à satisfação, devemos conhecer as necessidades $e$ os desejos dos pacientes.

Iniciamos nossa entrevista perguntando aos nossos entrevistados o que seria saúde para eles e o que obtivemos foram discursos com idéias diversas. A primeira idéia surgida é a de que, apesar de a saúde ser inerente ao cotidiano das pessoas, quando se pergunta "o que é saúde", elas têm dificuldade de expressar suas idéias:

O que é saúde é a gente ter saúde, não é? É ter saúde, ... Ixii, como a gente identifica que tem saúde, é difícil, né?...nunca pensei o que é ter saúde! DSC 5

Outra visão que emerge dos discursos é a visão centrada no biológico, como ausência de doença, onde a saúde estaria circunscrita à presença do médico $e$ do medicamento:

O remédio que eu necessito. DSC 9

A gente espera encontrá os médicos. DSC 12

Não demora muito pra atender. DSC 13

$\mathrm{Na}$ expectativa desses usuários, ainda aparece, também, a saúde como sendo o próprio serviço, e este estando relacionado ao "bom atendimento": 
A saúde é um lugar que você pode ir quando você precisa, e é bem atendida. DSC 1

No entanto, outros fatores agregam-se ao conceito de saúde, e este se amplia. A visão apresentada neste discurso nos faz ver que os usuários do serviço já apresentam outras expectativas quanto à saúde que eles devem ter:

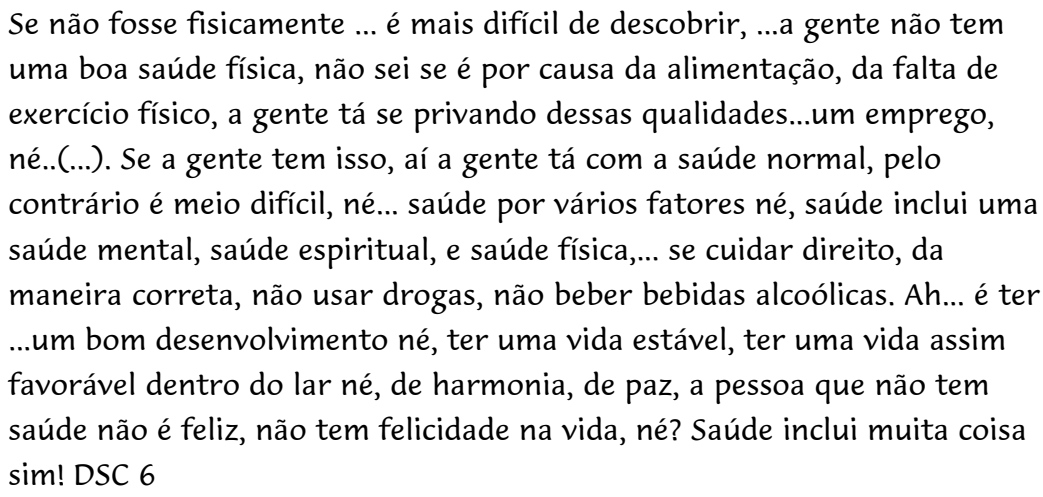

... médico, sei lá, que assim, te analise melhor, que..., dê mais atenção, atendimento mais prioritário,..e que o médico consiga acertar o problema da gente, né? Que ele escuta primeiro a gente, pra gente fala o que é,(...) .Você vai no médico se ele não examina da forma devida, não te atende direito, dá uma olhadinha em você e manda se vim embora,... como que ele vai sabe o que que eu tenho?... DSC 10

Segundo Stenzel et al. (2004), a satisfação resulta de juízos de diversos atributos, a resolubilidade da demanda é um desses, mas o acesso, a condição da atenção $e$ as condições do ambiente também o são. Ainda estes mesmos autores, citando Vaistman et al. (2003), referem que a percepção dos usuários quanto às práticas de saúde nos serviços se desenvolve pela articulação de, pelo menos, quatro dimensões: a subjetividade individual, a cultura da sociedade, a rede de relações instituídas ao longo da história e a situação em um determinado contexto ou a experiência imediata vivida.

Esses discursos nos demonstram como os usuários do serviço já conseguem manifestar a necessidade de serem atendidos por profissionais que não os reduzam a fragmentos de seu corpo físico e sim passem a enxergálos como seres inteiros, como uma característica da boa prática médica/ saúde: "o médico tem que examiná a pessoa, vê o que cê tá passando, pra vê o que a pessoa tem ou não tem,..." - DSC 8.

O segundo tema - a realidade que temos - tratou de verificar o que se passava nas práticas de serviço do Núcleo em estudo. Nesse momento, ao perguntarmos sobre o serviço, como se processava a consulta agendada, a consulta eventual, como era o atendimento por parte dos trabalhadores naquele local, as respostas dadas pelos entrevistados nos dariam a noção de como ocorria a produção do cuidado, ou até se ela ocorria ou não.

O acesso foi o primeiro quesito analisado e, segundo Starfield (2004), é a 
forma como a pessoa experimenta a característica de acessibilidade do serviço. A Atenção Primária de Saúde tem uma característica própria, que é a atenção ao primeiro contato: toda vez que existir uma demanda de saúde e esta tiver a entrada pela atenção primária, teremos potência para gerar melhor qualidade do encaminhamento da resolubilidade da necessidade apresentada; e essa potência está também condicionada com a relação estabelecida entre o usuário e os profissionais de saúde, a resolubilidade e a continuidade da atenção.

Houve um DSC que mostrava claramente a satisfação do usuário no que diz respeito ao local onde o núcleo se encontra geograficamente:

Ah, é bom,..bem pertinho de casa,...(...). Porque não é muito longe pra gente ir (...) Eu acho bom a localização dele...(...). DSC 38

Quanto à questão das instalações, outro atributo do serviço que pode ser avaliado subjetivamente pelos usuários no que diz respeito à satisfação na prestação da assistência, vemos que o primeiro discurso podia estar traduzindo o estado de acomodação às coisas da vida, como se fosse "assim mesmo"; é tão normal faltar manutenção nas estruturas das unidades públicas de saúde que vira coisa óbvia, não conseguindo nem perceber se estaria ruim ou não:

\section{(...). As outras coisas são como os outros postos mesmo. A gente acostuma! Eu estranhei o início, né? Mas agora já acostumei, não tenho o que queixar, não! Não tando chovendo em cima nem sol, minha filha, tá ótimo! DSC 45}

É também importante refletirmos se a satisfação no que diz respeito à questão das relações, o "se sentir em casa no Núcleo", não podia estar fazendo com que esteja realmente bom desta maneira, porque a expectativa foi "decifrada" e resolvida: foram bem atendidos, bem recebidos, ficando as instalações relegadas a outro plano. Ah pra mim tá normal, né? Não precisa mudar nada, não... (...). Acho que
tá bom, né? Acho que não precisa de reforma, não. DSC 41

Começaram, então, a aparecer outros discursos onde a insatisfação se fazia presente. Um primeiro discurso trazia a visão de saúde voltada para a atenção às doenças, em que a necessidade de se ter um prédio como um hospital era a expectativa presente:

Lá é uma casa de morada, né? Não é um prédio, é..assim que é adequado, qual um hospital: uma porta mais larga,...um tipo de assim,...um prédio assim de acordo com um Pronto-socorro ou Postos de Saúde, né? DSC 4

O "prédio próprio" citado no discurso acima carregava a imagem da arquitetura hospitalar, instituída pelas normas padronizadas pelas nossas instituições, com funções normalizadoras. No entanto, será que não 
precisamos pensar numa arquitetura menos improvisada que permita ou potencialize a mudança no modelo de atenção?

No processo, o fator "demora" para atendimento, consulta, procedimentos $e$ exames foi discutido com os entrevistadores, e os DSCs, às vezes, mostraram satisfação e, outras vezes, insatisfação.

Starfield (2004) traz a questão do tempo da seguinte maneira: a maioria das urgências deve ser atendida dentro de uma hora, em $90 \%$ dos casos; os quadros agudos devem demorar um dia para conseguir consulta, também em $90 \%$ dos casos; a rotina, os seguimentos têm de ser agendados para uma semana, em $90 \%$ dos casos; e, por último, o tempo de espera na Unidade para o atendimento deve ser menor do que trinta minutos, em $90 \%$ dos casos. Estamos realmente muito longe de ter essas metas de tempo estabelecidas desta maneira, como mostram os discursos a seguir:

Pra agendá consegui, só que demora, eles marcam pra 2, 3 meses, porque sempre tem gente na frente. DSC 19

Já esperei até 5 horas,..do meio-dia até 5 horas da tarde prá podê sê atendida, por exemplo eu vou de manhã e fala pra voltá à tarde,...se eu for sem tá marcada demora um pouquinho, né? Também já fui atendida na hora! Muitas vezes eu precisei fora da consulta e eles me atenderam prontamente,... gente aguarda a vez da gente. DSC 29

Os DSCs mostravam como ocorria esse tempo na Unidade, e como o tempo era "relativo", isto é, o que demora pra mim pode não demorar para o outro; havia também a referência de que era demorado, mas mesmo assim estava bom, parecia que o "bom atendimento" justificava a demora:

\footnotetext{
Ah... tá um pouco longe, né? Médio, né? E precisa demorá tanto... pelo menos o médico que eu fui, né? Mas qualquer lugar se demora pra tá ali no doutor,.então tem gente que tem que compreender... Pra mim tá bom! DSC 18
}

O terceiro tema, na verdade, foi um recorte do processo, pois entendíamos que tratava-se de uma avaliação de satisfação; porém, considerando os pressupostos desta pesquisa, enfatizamos aqui a questão das tecnologias leves, sendo analisados, neste momento, os DSCs que se referiam às relações.

A primeira idéia que emergia dos DSCs que construímos, na questão das diferenças dos serviços, trazia consigo os relacionamentos sendo entendidos como o "atender bem" ou "bom atendimento", confirmando o que diz Mehry (1998), de que a crise da saúde na visão dos usuários é quanto à falta de responsabilização e interesse em sua saúde:

O Núcleo atende as pessoa bem! A gente tem amizade, né? Eu senti que as enfermeiras são bastante atenciosa, elas conversam, te trata bem,... (...). ...você é tratado com mais amor que em outro lugar, porque elas já conhecem eu. É diferente o atendimento das meninas, dos médicos,...lá é um carinho todo diferente. A gente é bem acolhido sim, felizmente até hoje! DSC 49 
Eles são bem atenciosos... E é as coisa que mais a gente gosta é ser tratada bem, tratá igual a gente trata eles, né? Tratá muito bem... DSC 20

Percebemos, também, neste discurso, o tratamento de humano para humano: "tratá igual a gente trata eles, né?"; é "gente que cuida de gente" (Mishima et al., 2004), gente que acolhe mas também necessita ser acolhido. Os espaços de acolhimento são espaços de troca, coisas de humano, "eu dou e você me dá".

Franco e Magalhães Júnior (2003) referem que o exercício da clínica traduzido em atos de fala e escuta, em que o diagnóstico ganha a dimensão do cuidado, ao longo do tempo se perdeu, sendo substituído pelo ato prescritivo $e$ uma relação sumária entre profissional e usuário. Hoje, o que se tenta é, justamente, este resgate da produção do cuidado, pois somente assim poderemos agir no processo saúde/doença, produzindo, nos serviços, realmente saúde no seu conceito ampliado.

O quarto tema apontou as sugestões propostas pelos usuários para melhorar o serviço. $O$ nosso intuito aqui não foi apenas questionar e buscar dados para se realizarem ações junto com a participação social, mas também analisar, nesse instante, a satisfação $e$ a insatisfação da população quanto às questões levantadas anteriormente.

Uma das sugestões despontadas é ter o atendimento do Núcleo durante 24 horas do dia. Seria oportuno lembrar aqui que, talvez nesse momento, o que realmente os usuários sugerem é que o "bom atendimento" que eles têm no serviço deveria, na verdade, estar presente em todos os outros locais de assistência à saúde. Devemos refletir, então, que a qualidade da atenção é o que realmente importa para eles e, sem dúvida, com a responsabilização dos trabalhadores da equipe com a saúde deles. Vejamos o discurso:

\footnotetext{
Igual o Cuiabá, 24 horas. Trazer mais esse atendimento prás horas que num tem, igual no sábado e no domingo, ao invés da gente ir lá embaixo, é...trazer...pôr um...igual um pronto-socorro aí, com mais atendimento. Acho que seria adequado, né? DSC 57
}

Outra sugestão dos usuários seria interferir na questão do tempo: tempo de espera para exames, para atendimento, para resolução das demandas. A demora, como já vimos anteriormente, é motivo de grande irritabilidade e insatisfação por parte de quem usa os serviços do Núcleo. Como o atendimento oferecido é de boas relações, isto até é relevante, pois, ao final do processo, os usuários se satisfazem pela resolubilidade. O "tempo" deve ser uma preocupação por parte da equipe, no que diz respeito ao atendimento, pois está muito longe de se ter qualidade neste quesito. O usuário, no entanto, pede mais médicos para resolver a questão:

Ah, eu ia falar direto prá ele que precisa de mais médico ali, né? (...). Se eles mandasse mais, melhorava mais, né? Melhorava a nossa situação, aí não ia ficá demora de ninguém,... . Acho que precisaria ter mais médico! DSC 59 
Outro profissional já inserido nas Equipes de Saúde da Família é o dentista, e ele é lembrado pelos entrevistados como peça fundamental para a saúde dos usuários:

Lá no núcleo tem dentista e é como se não tivesse, né? Pra falar a verdade, pra trata de um dente tem que ir prô Cuiabá,.. .ali ela olha e manda prô Cuiabá! Ah, isso complica, né?Complica! Se tivesse um lugar, um posto de odontologia aqui, não seria mais fácil? DSC 61

O medicamento também é um fator a ser melhorado na opinião dos usuários. Ter o acesso ao serviço, com maior decodificação da simbologia trazida pelos usuários, com um melhor acolhimento e a resolução final de tudo pode estar na aquisição do medicamento:

Deveria ter aqui! Devia ter remédio aqui no Núcleo, né? É difícil,...que não tem parece que farmácia, né?(...). Ah,...que se tivesse aqui era melhor. DSC 26

Segundo Halal et al. (1994), a satisfação dos usuários estaria relacionada a conseguir o medicamento prescrito e que fosse conseguido no próprio serviço em que foi realizado o atendimento. Acreditamos que ter acesso ao medicamento e tê-lo na unidade seria a melhor e mais fácil forma de adquirir o medicamento, portanto, o melhor para o usuário.

\section{Conclusões}

Em nosso estudo, buscamos avaliar a satisfação/insatisfação do usuário, preferencialmente no que diz respeito às tecnologias leves. Terminamos a investigação com a evidência de que os usuários do serviço estudado dão, sim, muita importância para o modo do "trato", valorizando a incorporação dessas tecnologias nos espaços de produção em saúde. Eles demonstram estranhamento quando deixam de ser cumprimentados e chamados pelo nome. Ao mesmo tempo, destacam formas de atendimento, nos diversos momentos do processo de trabalho, valorizando atos que os reconhecem como seres humanos, tanto quanto os trabalhadores que os atendem, $e$ ainda quando esses trabalhadores produzem, no processo de atendimento, o compromisso com a atenção daqueles que demandam o serviço do Núcleo. É possível apreender o reconhecimento dos usuários no que diz respeito à forma do trabalhador estabelecer uma relação diferenciada para com eles, relação acolhedora, com aspectos ligados ao vínculo, compromisso, responsabilização pela saúde e autonomia. Nesse sentido, sentimo-nos autorizadas a afirmar que as tecnologias leves são geradoras de satisfação, quando voltadas à prática do cuidado em saúde.

Na pesquisa também foi se tornando evidente que os usuários clamam para que o serviço disponibilize recursos tecnológicos para resolver problemas de ordem biológica; destacam insuficiências de recursos de ordem de pessoal e mesmo de ordem estrutural, como a não-distribuição de medicamentos e a ausência de equipamento odontológico $e$, ainda, a demora para realização de exames solicitados. Reforçando, desta maneira, a 
necessidade da disponibilidade de diferentes tecnologias (dura, leve-dura $e$ leve) nos processos de produção em saúde.

Outro aspecto que merece reflexão é o horário de funcionamento, quando os usuários sugerem atendimento 24 horas. Será que esta observação não poderia disparar a reavaliação do horário atual? Esse horário responde à necessidade de quem? Poderia ser revisto, sem com isso estar indicando horário ininterrupto de funcionamento?

A demonstração da satisfação dos usuários pela incorporação das tecnologias leves não deixou os usuários tomados por zonas de cegueira ou impedidos de manifestar insatisfações decorrentes do processo de trabalho $e$ da falta de investimentos voltados para atender às necessidades daqueles que justificaram a implantação do serviço. Esta circulação pelos caminhos da satisfação e insatisfação demonstra que, sem dúvida, ainda precisamos de muito investimento e, também, de incorporar a prática de avaliação do cotidiano, visando a instituir mudanças na perspectiva dos princípios norteadores da Atenção Primária à Saúde e no fortalecimento do Sistema único de Saúde, tomando o usuário como o objeto central do processo de trabalho.

\section{Referências}

ALMEIDA, M.C.P. O trabalho de enfermagem e sua articulação como processo de trabalho em saúde coletiva: rede básica de saúde. 1991. Tese (Livre-Docência) - Escola de Enfermagem de Ribeirão Preto, Universidade de São Paulo, Ribeirão Preto.

BOFF, L. Saber cuidar: ética do humano, compaixão pela terra. Petrópolis: Vozes, 1999.

BRASIL. Ministério da Saúde. Saúde da Família: uma estratégia para a reorientação do modelo assistencial. Brasília, 1998.

Ministério da Saúde. Promoção da saúde: Carta de Ottawa, Declaração de Adelaide, Declaração de Sundsvall, Declaração de Bogotá. Brasília, 1996.

CONTANDRIOPOULOS, A.P.; CHAMPAGNE, F.; DENIS, J.L.; PINEAULT, R. A avaliação na área da saúde: conceitos e métodos. In: HARTZ, Z.M.A. (Org.). Avaliação em saúde: dos modelos conceituais à prática na análise de implantação de programas. Rio de Janeiro: Fiocruz, 1997. p. 29-48.

DONABEDIAN, A. The seven pillars of quality. Arch. Pathol. Lab. Méd., v.114, p.1115-8, 1990.

FERRI, S.M.N. As tecnologias leves como geradoras de satisfação em usuários de uma unidade de saúde da família - elemento analisador da qualidade do cuidado prestado?. 2006. Dissertação (Mestrado) - 
Programa de Pós-Graduação de Enfermagem em Saúde Pública, Escola de Enfermagem de Ribeirão Preto, Universidade de São Paulo, Ribeirão Preto.

FRANCO, T.B.; MAGALHÃES JR., H.M.M. Integralidade na assistência à saúde: a organização das linhas do cuidado. In: MERHY, E.E. (Org.). O trabalho em saúde: olhando e experienciando o SUS no cotidiano. São Paulo: Hucitec, 2003. p.125-34.

HALAL, I.S.; SPARRENBERGER, F.; BERTONI, A.M.; CIACOMET, C.; SEIBEL, C.E.; LAHUDE, F.M.; MAGALHÃES, G.A.; BARRETO, L.; LIRA, R.C.A. Avaliação da qualidade da assistência primária à saúde em localidade urbana da região sul do Brasil. Rev. Saúde Pública, v.18, n.2, p.131-6, 1994.

HARTZ, Z.M.A. Explorando novos caminhos na pesquisa avaliativa das ações de saúde. In: (Org.). Avaliação em saúde: dos modelos conceituais à prática na análise da implantação de programas. Rio de Janeiro: Fiocruz, 1997. p.19-28.

LEFÈVRE, F.; LEFÈVRE, A.M.C.; TEIXEIRA, J.J.V. O discurso do sujeito coletivo: uma nova abordagem metodológica em pesquisa qualitativa. Caxias do Sul: EDUCS, 2000.

MALIK, A.M.; SCHIESARI, L.M.C. Qualidade na gestão local de serviços e ações de saúde. São Paulo: Faculdade de Saúde Pública da Universidade de São Paulo, 1998. (Série Saúde e Cidadania, v.3).

MENDES GONÇALVES, R.B. Tecnologia e organização social das práticas de saúde. São Paulo: Hucitec-Abrasco, 1994.

MERHY, E. E. Saúde: a cartografia do trabalho vivo. São Paulo: Hucitec, 2002.

A perda da dimensão cuidadora na produção da saúde - uma discussão do modelo de assistência e da intervenção no seu modo de trabalhar a assistência. In: CAMPOS, C.R.; MALTA, D.C.; REIS, A.T.; SANTOS, A.F.; MEHRY, E.E. (Orgs.). Sistema Único de Saúde em Belo Horizonte: reescrevendo o público. São Paulo: Xamã, 1998. p.103-20.

MEHRY, E.E.; CHAKKOUR, M.; STÉFANO, E.; STÉFANO M.E.; SANTOS, C.M.; RODRÍGUEZ, R.A. Em busca de ferramentas analisadoras das tecnologias em saúde: a informação e o dia a dia de um serviço, interrogando e gerindo trabalho em saúde. In: MERHY, E.E.; ONOCKO, R. (Orgs.). Agir em saúde: um desafio para o público. São Paulo: Hucitec, 1997. p.113-50.

MISHIMA, S.M.; PEREIRA, M.J.B.; MATUMOTO, S.; NASCIMENTO, M.Â.A.; FORTUNA, C.M.; TEIXEIRA, R.A. O desafio do cuidar em saúde coletiva. In: FÓRUM MINEIRO DE ENFERMAGEM DIVERSIFICANDO O CUIDAR, 4., 2004, Uberlândia. Anais... Uberlândia, 2004. p.22-34.

NASCIMENTO, M.A.A.; MISHIMA, S.M. Enfermagem e o cuidar - construindo uma prática de relações. J. Assoc. Bras. Enferm., v.46, n.2, p.12-5, 2004.

OLIVEIRA, F.J.A. A contribuição da antropologia nos estudos de satisfação e a avaliação dos serviços de saúde no nível de atenção primária à saúde: vale a pena ouvir o que os usuários têm a nos dizer? Momento Perspect. Saúde, v.11, n.1, p.18-32, 1998.

ORGANIZAÇÃO MUNDIAL DA SAÚDE - OMS. Alma Ata 1978. Cuidados Primários de Saúde. Relatório da Conferência Internacional sobre cuidados primários de saúde. Brasília: OMS/UNICEF, 1979.

PEREIRA, M.J.B. O trabalho da enfermeira no serviço de assistência domiciliar: potência para (re)construção da prática de saúde e de enfermagem. 2001. Tese (Doutorado) - Escola de Enfermagem de Ribeirão Preto, Universidade de São Paulo, Ribeirão Preto.

PESSINI, L. O cuidado em saúde. O Mundo da saúde, v. 24, n. 4, p.235-6, 2000.

RAGGIO, A.; GIACOMINI, C.H. A permanente construção de um modelo de saúde. Divulg. Saúde para Debate, n.6, p.9-16, 1996.

SANTOS, S.R.; LACERDA, M.C.N. Fatores de satisfação e insatisfação entre os pacientes assistidos pelo SUS. Rev. Bras. Enferm., v.52, n.1, p.43-53, 1999. 
SILVA JR., A.G.S.; MEHRY, E.E.; CARVALHO, L.C. Refletindo sobre o ato de cuidar da saúde. In: PINHEIRO, R.; MATTOS, R.A. (Orgs.). Construção da integralidade: cotidiano, saberes e práticas em saúde. Rio de Janeiro: UERJ/IMS/ Abrasco, 2003. p.113-28.

SOUZA,E.M.; PEREIRA, M.G. A satisfação dos usuários na avaliação dos serviços de saúde. Brasília Médica, v.36, n. 1/2, p.33-6, 1999.

STARFIELD, B. Atenção primária: equilíbrio entre necessidades de saúde, serviços e tecnologia. Brasília: Unesco/Ministério da Saúde, 2004.

STENZEL, A.C.B.; MISOCZKY, M.C.A.; OLIVEIRA, A.I. Satisfação dos usuários de serviços públicos de saúde. In: MISOCZKY, M.C.; BORDIN, R. (Orgs.). Gestão local em Saúde: práticas e reflexões. Porto Alegre: Dacasa Editora, 2004. p.87-102.

UCHIMURA, K.Y.; BOSI, M.L.M. Qualidade e subjetividade na avaliação de programas e serviços em saúde. Cad. Saúde Pública, v.18, n.6, p.1561-9, 2002.

VAISTMAN, J.; FARIAS, L.O.; MATTOS, A.M.; CAMPOS FILHO, A.C. Metodologia de elaboração do índice de percepções organizacionais. Cad. Saúde Pública, v.19, n.6, p.1-18, 2003.

FERRI, S.M.N. ET AL. Las tecnologías ligeras como generadoras de la satisfacción en usuarios de una unidad de salud de la familia. Interface - Comunic., Saúde, Educ., v.11, n.23, p.515-29, set/dez 2007.

El objetivo de esta investigación ha sido evaluar la calidad de la ayuda dada en un núcleo de la salud de la familia, enfocando la satisfacción de los usuarios a partir de las tecnologías ligeras; así como analizar aspectos de esta ayuda, los productores de la satisfacción e insatisfacción, en lo que se refiere al vínculo, a la responsabilidad, a la posible resolución, a las expectativas, a las relaciones, a la comodidad y acceso e identificar recomendaciones para las intervenciones locales. Tras realizar una caracterización general de la población atendida en el servicio estudio, se seleccionan los sujetos participantes de la investigación. La recogida de datos se efectuó por medio de la entrevista semi-estructurada. El planteamiento fue de naturaleza cualitativa y los datos se han ordenado por el método del Discurso de Sujeto Colectivo (DSC). El análisis revela la importancia que los usuarios de este servicio atribuyen a las tecnologías ligeras pero también la necesidad de disminuir el tiempo de espera para las consultas y los encaminamientos y para conseguir acceso a las medicinas y a la atención odontológica en el propio servicio; factores que llevan a gran insatisfacción de estos usuarios.

PALABRAS CLAVE: Evaluación. Satisfacción de los consumidores. Salud de la familia. 


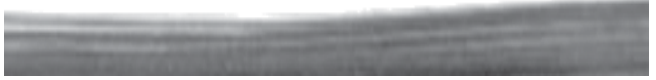

